Harada, T. \& Spencer, B. (1960). J. gen. Microbiol. 22, 520-527

\title{
Choline Sulphate in Fungi
}

\author{
By T. HARADA* AND B. SPENCER \\ Department of Biochemistry, University of Wales, Newport Road, Cardiff
}

\begin{abstract}
SUMMARY: The occurrence of choline sulphate in 32 fungi and 9 bacteria was investigated by incorporating $\mathrm{Na}_{2}{ }^{35} \mathrm{SO}_{4}$ into culture media and subsequently identifying radioactive choline sulphate in cell extracts by chromatography and radioautography. The production of choline sulphate appears to be restricted to higher fungi since it was not found in any of the tested Phycomycetes. Of the Ascomycetes, the Endomycetales did not synthesize choline sulphate but the mycelia of the Sphaeriales did accumulate the compound. The Basidiomycetes and all the Fungi Imperfecti, except Torulopsis utilis, were choline sulphate positive. The choline sulphate negative organisms, including all of the bacteria tested, could not be induced to produce choline sulphate by adding large amounts of choline to the culture media or by growing on chemically defined media in which inorganic sulphate was the sole sulphur source. On the other hand, Aspergillus oryzae produced choline sulphate on a minimal medium containing inorganic sulphate, cysteine, cysteic acid or taurine as sulphur sources. The distribution of choline sulphate production has been discussed in terms of the absence or presence of the enzyme choline sulphokinase.
\end{abstract}

The role of choline sulphate, $-\mathrm{O}_{3} \mathrm{~S} \cdot \mathrm{O} \cdot \mathrm{CH}_{2} \cdot \mathrm{CH}_{2} \cdot \mathrm{N}^{+}\left(\mathrm{CH}_{3}\right)_{3}$, in the sulphur metabolism of fungi is still a matter of controversy. This sulphate ester has been isolated from Aspergillus sydowi (Woolley \& Peterson, 1937) and Penicillium chrysogenum (De Flines, 1955; Stevens \& Vohra, 1955) in yields greater than $0.2 \%$ of the dry weight of the mycelium; similar high concentrations have also been found in lichens of the Rocella spp. (Lindberg, 1955a) and the red alga Gelida cartilaginum (Lindberg, 1955 b). The accumulation of such relatively large amounts of choline sulphate suggests that it is a storage compound, an end- or by-product of sulphate or choline metabolism, or an excretory compound, rather than an active intermediate in the utilization of the sulphur of inorganic sulphate. However, from the results of competitive metabolism experiments, it has been stated (Egami \& Itahashi, 1951 ; Itahashi, 1954) that choline sulphate is indeed an intermediate in the utilization of sulphate by Aspergillus oryzae. On the other hand, similar experiments with $P$. chrysogenum (Stevens \& Vohra, 1955) led to the opposite conclusion, since the sulphur of inorganic sulphate was used preferentially to that of choline sulphate for the synthesis of penicillin. It seems clear, however, that choline sulphate and inorganic sulphate do share some common metabolic pathway since mutant strains of Aspergillus nidulans and $\boldsymbol{P}$. notatum which did not utilize inorganic sulphur as the sole sulphur source also failed to utilize choline sulphate, while the parent strains grew readily on either sulphur source (Hockenhull, 1948, 1949). The detection of 'ester sulphate' in the mycelia of

\footnotetext{
* Present address: Institute of Scientific and Industrial Research, Osaka University, Japan.
} 


\section{Choline sulphate in fungi}

various Penicillium spp. and Aspergillus spp. by Raistrick \& Vincent (1948) suggests that choline sulphate or some similar compound might be produced by more fungi than is now known. Since the extent of the occurrence of choline sulphate should indicate its relative importance, a survey of representative fungi has now been made as the first stage of a further investigation of the metabolism of this compound.

\section{METHODS}

Culture media. Organisms were grown mainly in Czapek-Dox medium in which inorganic sulphate (plus $100 \mu \mathrm{c}$. carrier-free $\mathrm{Na}_{2}{ }^{35} \mathrm{SO}_{4} /$ l. in some experiments) was the only sulphur source; or in a glucose peptone yeast-extract medium containing (g./l. water): 20, glucose; 10, Bacto-peptone; 3, Bacto yeast extract; $0 \cdot 6, \mathrm{Na}_{2} \mathrm{SO}_{4} ; 100 \mu \mathrm{c} . \mathrm{Na}_{2}{ }^{35} \mathrm{SO}_{4}$. The latter medium was sometimes supplemented with a total of $1 \cdot 2 \mathrm{~g}$. choline/l. added daily in $0 \cdot 4 \mathrm{~g} . /$. amounts. A more complex chemically defined medium than Czapek-Dox was used for certain fungi; this contained per litre: glucose, $10 \mathrm{~g}$; asparagine, 1.5 g.; $\mathrm{NH}_{4} \mathrm{H}_{2} \mathrm{PO}_{4}, 1.5$ g.; $\mathrm{KH}_{2} \mathrm{PO}_{4}, 1.0$ g.; $\mathrm{MgSO}_{4} .7 \mathrm{H}_{2} \mathrm{O}, 0.5$ g.; $\mathrm{NaCl}, 0.5$ g.; inositol, $20 \mathrm{mg}$.; thiamine, $1 \mathrm{mg}$.; biotin, $1 \mu \mathrm{g}$.; carrier-free $\mathrm{Na}_{2}{ }^{35} \mathrm{SO}_{4}, 100 \mu \mathrm{c}$. Cultures $\left(200 \mathrm{ml}\right.$.) were grown for 4-6 days at $27^{\circ}$ with shaking.

Preparation of mycelial extracts. The harvested mycelia were washed well with water and dried in vacuo over $\mathrm{P}_{2} \mathrm{O}_{5}$ for 2 days. Extracts of the dried mycelia were prepared by suspending $200 \mathrm{mg}$. mycelium in $10 \mathrm{ml}$. water and heating in a boiling water bath for $5 \mathrm{~min}$. After cooling, $200 \mathrm{mg}$. alumina was added and the mixture ground in a glass homogenizer. To the supernatant fluid obtained after centrifugation was added $2 \mathrm{ml}$. $n$-butanol; the mixture was then shaken for $30 \mathrm{~min}$., centrifuged and the protein-free aqueous solution freezedried. The dry material was dissolved in $0.2 \mathrm{ml}$. water. In cases where high concentrations of polysaccharide made the extract slimy, the freeze-dried material was dissolved in $0.1 \mathrm{ml}$. water and the polysaccharides precipitated by adding $0.1 \mathrm{ml}$. ethanol. For chromatography 10 and $20 \mu \mathrm{l}$. samples of the final extract was used routinely in spotting on the papers.

Preparation of extracts of culture media. Fungi were grown on the complex chemically defined medium but containing $0 \cdot 4 \%$ glucose and $600 \mu \mathrm{c} . \mathrm{Na}_{2}{ }^{35} \mathrm{SO}_{4} /$ $200 \mathrm{ml}$. After growth for 4 days, the mycelium was separated and $200 \mathrm{ml}$. of the clear supernatant fluid was freeze-dried. The dried material was dissolved in $5 \mathrm{ml}$. water and desalted by using the Wood dialyser (Wood, 1956); choline sulphate does not migrate in an electric field. The solution was then freeze-dried and dissolved in $50 \mu \mathrm{l}$. water. For chromatography a $10 \mu \mathrm{l}$. sample was used.

Chromatographic detection of choline sulphate. Using Whatman no. 1 papers, three solvent systems were tested for the degree of separation of choline sulphate from other sulphur-containing compounds likely to be found in the mycelial extracts (Table 1). As well as the more obvious S-containing compounds, glyceryl taurine, monomethyl taurine and cysteinolic acid were also tested since they have been found with choline sulphate in extracts of certain algae (Wickberg, 1956, 1957). Of the systems tested, acetone/water (9:1) for 
$3 \mathrm{hr}$. was subsequently used for the routine testing of the fungal extracts. In this rapidly moving solvent, ${ }^{35} \mathrm{SO}_{4}{ }^{--}$, which was sometimes present in the extracts in high concentration, remained at the origin and choline sulphate could be clearly distinguished from the other S-containing compounds. It is interesting that Strauss \& Minagawa (1959) noted a non-ninhydrin staining spot containing radioactive ${ }^{35} \mathrm{~S}$ at $\boldsymbol{R}_{F} \mathbf{0 . 9 6}$ in phenol/water chromatograms of a methionine-requiring mutant of Neurospora crassa. This unknown spot might be choline sulphate (cf. Table 1).

Table 1. $R_{F}$ values of $S$-containing compounds in different solvent systems, on Whatman no. 1 papers

\begin{tabular}{|c|c|c|c|}
\hline & $\begin{array}{c}\text { Phenol/water } \\
(80: 20) \\
\text { for } 16 \mathrm{hr} \text {. }\end{array}$ & $\begin{array}{c}\text { Acetone/water } \\
(9: 1) \\
\text { for } 3 \mathrm{hr} . \\
R_{y} \text { values }\end{array}$ & $\begin{array}{c}\text { Butanol/ } \\
\text { ethanol/water } \\
(4: 1: 5) \\
\text { for } 16 \mathrm{hr} \text {. }\end{array}$ \\
\hline $\mathrm{Na}_{2} \mathrm{SO}_{4}$ & 0.05 & $\mathbf{0}$ & $\mathbf{0}$ \\
\hline Choline sulphate & 0.94 & $0 \cdot 26$ & $0 \cdot 15$ \\
\hline Taurine & 0.39 & 0.08 & $0 \cdot 11$ \\
\hline Cysteine & $\mathbf{0} \cdot \mathbf{8 0}$ & - & - \\
\hline Cystine & 0.23 & $0 \cdot 17$ & $0 \cdot 21$ \\
\hline Methionine & 0.83 & $0 \cdot 10$ & 0.30 \\
\hline Glyceryl taurine & 0.59 & $0 \cdot 08$ & - \\
\hline Monomethyl taurine & 0.71 & $0 \cdot 13$ & - \\
\hline Cysteinolic acid & $\mathbf{0 . 3 3}$ & $0 \cdot 10$ & - \\
\hline Glutathione & $0 \cdot 11$ & - & 0.03 \\
\hline
\end{tabular}

Choline sulphate was detected on the chromatograms by spraying with $5 \%$ $(\mathrm{v} / \mathrm{v})$ perchloric acid and heating at $70^{\circ}$ for $5 \mathrm{~min}$.; at higher temperatures the paper was destroyed. The location of inorganic sulphate liberated was detected as a yellow spot on a pink background by using the barium chloride + sodium rhodizonate technique of Schneider \& Lewbart (1956). The lower limit of detection of choline sulphate by this method was $4 \mu \mathrm{g}$., corresponding to a concentration of $100 \mu \mathrm{g}$. choline sulphate/g. dried mycelium when $40 \mu \mathrm{l}$. of extract was spotted. In experiments using ${ }^{35} \mathrm{SO}_{4}^{--}$, radioautograms of the chromatograms were prepared by using Ilford Industrial B X-ray film and an exposure time of 5-10 days. Under the conditions used and with a $10 \mu l$. sample for chromatography the limit of detection of choline sulphate by the radioactive method was better than $1 \mu \mathrm{g}$. $/ \mathrm{g}$. dry mycelium. When extracts of the culture medium were used the limit of detection was $0.5 \mu \mathrm{g} . / 100 \mathrm{ml}$.

\section{RESUL'TS}

With the acetone/water solvent typical chromatograms of mycelial extracts showed a radioactive trail, or occasionally distinct spots, between the sulphate spot at the origin and the region $\boldsymbol{R}_{F} \mathbf{0 \cdot 2 0}$. This region of the chromatogram also showed a number of ninhydrin-staining spots. A clearly distinguished spot, $R_{F} \mathbf{0} \cdot \mathbf{2 6 0}$, occurred when choline sulphate was present. No other radioactivity was observed on the chromatograms except in the case of Pichia membranaefaciens which showed a strong spot at $R_{F}$ 0.56. The latter material did not 


\section{Choline sulphate in fungi}

appear to be a sulphate ester since chromatograms of the Pichia extract after hydrolysis with $2 \mathrm{~N}-\mathrm{HCl}$ for $1 \mathrm{hr}$. at $100^{\circ}$ still showed a radioactive spot at $\boldsymbol{R}_{\boldsymbol{F}}$ 0.56. In cases where the radioactive choline sulphate spot was strong, the presence of ester sulphate on the chromatogram was confirmed by hydrolysis and detection of the liberated sulphate by the $\mathrm{BaCl}_{2}+$ rhodizonate technique. Further identification of choline sulphate in the extracts was made in a few cases by the observation of a radioactive spot $R_{F} 0.94$ on phenol/water chromatograms.

A total of 32 fungi and 9 representative bacteria were tested for choline sulphate production (Table 2). The concentration of choline sulphate in the mycelia of the 20 fungi which produced this compound differed considerably. By far the most potent producers were Aspergillus nidulans, A. oryzae and Neurospora crassa (Commonwealth Mycological Institute (CMI) 53238); Penicillium notatum and $\boldsymbol{P}$. aurantiobrunneum produced small amounts only detectable by the radioautographic technique. Choline sulphate appeared to occur mainly in the mycelia and only small amounts were found in the culture filtrates.

Choline sulphate was formed in the mycelium of Aspergillus oryzae after 5 days growth in Czapek-Dox medium when cysteine, taurine or cysteic acid were substituted for inorganic sulphate. When these organic sulphur compounds served as the sole sulphur source a yellow spot, $R_{F} 0 \cdot 0$, was shown by the $\mathrm{BaCl}_{2}+$ rhodizonate technique, suggesting that inorganic sulphate had been formed. The cholineless strain of Neurospora crassa, CMI 19419 (Horowitz $\&$ Beadle, 1943), produced choline sulphate in the presence of added choline (Table 2). Choline sulphate could replace choline as the essential micronutrient for this fungus (cf. Stevens \& Vohra, 1955).

Some fungi did not appear to accumulate choline sulphate in their mycelia when grown on the glucose peptone yeast-extract medium. The lack of choline was not a restricting factor since, with selected strains, the addition of $0.4 \mathrm{~g}$. choline/l. to the glucose peptone yeast-extract medium on four occasions during growth failed to initiate choline sulphate production (Table 2). The use of the complex chemically defined medium in which inorganic sulphate was the only significant source of sulphur was also ineffective (Table 2). Since the permeability of these fungi might be different from those in which choline sulphate occurs in the mycelium the culture media from Rhizopus stolonifer and baker's yeast were tested for choline sulphate; these were negative. None of the bacteria produced choline sulphate (Table 2).

One further point which was established was that representative fungi from both the choline sulphate-producing and non-producing groups could utilize inorganic sulphate as the sole sulphur source. As well as those fungi listed in Table 2, which were grown on Czapek-Dox or the complex chemically defined medium, Rhizopus stolonifer (-) Eremothecium ashbyi, Nematospora gossypii, Mucor hiemalis, Cunninghamella echinulata, Saccharomyces cerevisiae, Neurospora crassa (CMI 53238) were all able to grow on the complex defined medium. Both strains of Aerobacter aerogenes tested utilized the sulphur of inorganic sulphate. 


\section{DISCUSSION}

The synthesis of choline sulphate by Penicillium chrysogenum is known to involve the transfer of sulphate from $3^{\prime}$-phosphoadenosine-5' -phosphosulphate (PAPS) to choline under the influence of a specific transferase, choline sulphokinase (Kaji \& McElroy, 1958). With baker's yeast it has been shown that the formation of PAPS is a two-stage process; the first stage involves the reversible action of an ATP-sulphurylase to give adenosine-3'-phosphosulphate (APS) and pyrophosphate and this is followed by a non-reversible phosphorylation of APS by a specific APS-kinase to give PAPS (Bandurski, Wilson \& Squires, 1956). The presence of an efficient pyrophosphatase is necessary to remove pyrophosphate which tends to reverse the first reaction.

The inability of a fungus to produce choline sulphate might therefore be due to several reasons. One factor, the insufficient supply of choline, has been ruled out in the present investigation. Another point which was considered was that the PAPS and choline sulphate systems may be 'dormant' when the organism has an adequate supply of easily assimilated sulphur, such as cysteine. Against this possibility is the fact that the fungi which did not synthesize choline sulphate on a glucose peptone yeast-extract medium grew on a medium in which inorganic sulphur was the only significant sulphur

\section{Table 2. A survey of the occurrence of choline sulphate in some fungi}

Culture media were : (1) glucose peptone yeast extract; (2) glucose peptone yeast-extract + 1.2 g. choline chloride/l.; (3) Czapek-Dox medium ; (4) chemically defined medium containing asparagine, inositol, biotin, etc. For details see text.

\begin{tabular}{|c|c|c|}
\hline & Medium & sulph \\
\hline \multicolumn{3}{|l|}{ Phycomycetes } \\
\hline \multicolumn{3}{|l|}{ Mucorales } \\
\hline Rhizopus stolonifer (+) CMI 57761 & $1,2,4$ & - \\
\hline R. stolonifer (-) CMI 57762 & 1,2 & - \\
\hline Mucor hiemalis (-) CMI 21217 & 1 & - \\
\hline Phycomyces blakesleeanus CMI 21156 & 1 & - \\
\hline Cunninghamella echinulata CMI 44534 (a) & 1 & - \\
\hline \multicolumn{3}{|l|}{ Ascomycetes } \\
\hline \multicolumn{3}{|l|}{ Endomycetales } \\
\hline Eremothecium ashbyi CMI 31269 & 1,2 & - \\
\hline Nematospora gossypii CMI 31279 & 1,2 & - \\
\hline Saccharomyces cerevisiae CMI 19391 & 1 & - \\
\hline S. cerevisiae var. ellipsoideus NCYC 57 & 1 & - \\
\hline Baker's yeast & $1,2,4$ & - \\
\hline Pichia membranaefaciens NCYC 51 & 1 & - \\
\hline \multicolumn{3}{|l|}{ Sphaeriales } \\
\hline Neurospora crassa CMI 19419 & 1,2 & + \\
\hline N. crassa CMI 53238 & 2 & + \\
\hline N. sitophila (+) CMI 63919 & 1,2 & + \\
\hline N. sitophila (-) CMI 63920 & 2 & + \\
\hline \multirow{2}{*}{\multicolumn{3}{|c|}{$\begin{array}{c}\text { Basidiomycetes } \\
\text { Ustilaginales }\end{array}$}} \\
\hline & & \\
\hline Ustilago scitaminea CMI 35616 & $\mathbf{1}$ & + \\
\hline
\end{tabular}




\section{Choline sulphate in fungi}

Table 2 (cont.)

\begin{tabular}{|c|c|c|}
\hline Je $2\left(\cos x_{0}\right)$ & Medium & $\begin{array}{l}\text { Presence } \\
\text { of choline } \\
\text { sulphate }\end{array}$ \\
\hline \multicolumn{3}{|l|}{ Fungi Imperfecti } \\
\hline \multicolumn{3}{|l|}{ Moniliales } \\
\hline \multicolumn{3}{|l|}{ Sporobolomycetaceae } \\
\hline Sporobolomyces roseus CMI 43529 & 2 & + \\
\hline S. salmonicolar CMI 56578 & 2 & + \\
\hline \multicolumn{3}{|l|}{ Moniliaceae } \\
\hline Aspergillus terreus LSHTM Ab2 & $\mathbf{3}$ & + \\
\hline A. oryzae CMI 17299 & $\mathbf{3}$ & + \\
\hline A. sydowii CMI 63904 & 3 & + \\
\hline A. nidulans CMI 16643 & 3 & + \\
\hline Penicillium citreo-roseum LSHTM P22 & 3 & + \\
\hline P. chrysogenum CMI 62728 & $\mathbf{3}$ & + \\
\hline P. notatum LSHTM P45 & $\mathbf{3}$ & + \\
\hline P. aurantio-brunneum LSHTM P2 & 3 & + \\
\hline Oedocephalum glomerulosum CMI 60070 & 2 & + \\
\hline Trichoderma viride sp. & 2 & + \\
\hline \multicolumn{3}{|l|}{ Pseudosaccharomycetaceae } \\
\hline Torulopsis utilis CMI 23311 & $1,2,4$ & - \\
\hline Rhodotorula rubra CMI 38784 & 1 & + \\
\hline \multicolumn{3}{|l|}{ Tuberuculariaceae } \\
\hline Fusarium sp. & & + \\
\hline \multicolumn{3}{|l|}{ Dermatiaceae } \\
\hline Cladosporium cladosporioides CMI 49625 & $\mathbf{1}$ & + \\
\hline \multicolumn{3}{|l|}{ Bacteria } \\
\hline Pseudomonas pyocyanus NCTC 8097 & 2 & - \\
\hline P. fluorescens NCTC 4725 & 2 & - \\
\hline Escherichia coli NCTC 8196 & 2 & - \\
\hline Aerobacter aerogenes ATCC 9621 & 1,2 & - \\
\hline A. aerogenes ATCC 7256 & 1,2 & - \\
\hline Staphylococcus aureus NCTC 6571 & 2 & - \\
\hline Streptococcus faecalis NCTC 8966 & 2 & - \\
\hline Bacillus subtilis NCTC 2116 & 2 & - \\
\hline Streptomyces albus sp. & 1 & - \\
\hline \multicolumn{3}{|c|}{$\begin{aligned} \text { ATCC } & =\text { American Type Culture Collection. } \\
\text { CMI } & =\text { Commonwealth Mycological Institute. } \\
\text { SHTM } & =\text { London School of Hygiene and Tropical Medicine. } \\
\text { NCTC } & =\text { National Collection of Type Cultures. } \\
\text { NCYC } & =\text { National Collection of Yeast Cultures. }\end{aligned}$} \\
\hline
\end{tabular}

source, but no choline sulphate synthesis resulted (Table 2). Many other factors have been investigated in a separate investigation (Spencer \& Harada, 1959) which shows that the fungi which utilize the sulphur of inorganic sulphate all synthesize PAPS and that the failure to produce choline sulphate is due to the absence of choline sulphokinase.

The systematics of choline sulphate synthesis can therefore be related to the presence or absence of choline sulphokinase (see Table 2). This enzyme would appear to be absent from the lower fungi since none of the Phycomycetes produced choline sulphate. In the Ascomycetes, none of the Endomycetales possess choline sulphokinase but the enzyme is present in the Sphaeriales. All the Fungi Imperfecti, except Torulopsis utilis, were choline sulphate positive. The degree of concurrence between the presence or absence of choline 
sulphokinase and accepted taxonomic division is high, and the exception of T. utilis (syn. Candida utilis) becomes rather outstanding (Table 2). An unconfirmed observation of Windisch (1948) that $T$. utilis shows ascospore formation would place this organism in the Endomycetales, a group which does not synthesize choline sulphate. It is also possible to place the Sporobolomyces in the Basidiomycetes, and many of the aspergilli and penicillia as Eurotiales in the Ascomycetes, without affecting the relationship between choline sulphate production and taxonomy. However, by extension of this type of argument the position of Rhodotorula rubra might well become ambiguous with respect to the systematics of choline occurrence.

Both choline sulphate-producing and non-producing fungi can utilize the sulphur of inorganic sulphate for growth purposes. Two alternative schemes for sulphate assimilation can therefore be proposed: (i) that both classes of fungi metabolize $\mathrm{SO}_{4}^{--}$in the same manner and that choline sulphate formation is only a side reaction; (ii) that the two classes metabolize sulphate differently, choline sulphate formation being an obligatory stage but only in the choline sulphate-producing fungi. Aerobacter aerogenes, Pseudomonas pyocyanus, $\boldsymbol{P}$. fluorescens and Escherichia coli, which are known from the literature to be capable of using inorganic sulphate, may possess a sulphate-metabolizing system like that of the fungi which do not form choline sulphate.

The authors wish to thank Professor J. H. Birkinshaw, Mr R. Harvey and Mr E. C. Hill for some fungal and bacterial cultures and Dr B. Wickberg for the gift of taurine derivatives. The receipt of a Royal Society Grant in support of this investigation is gratefully acknowledged.

\section{REFERENCES}

Bandurski, R. S., Wilson, L. G. \& Squires, C. L. (1956). The mechanism of 'Active Sulfate' formation. J. Amer. chem. Soc. 78, 6408.

DE Flines, J. (1955). The occurrence of a sulfuric acid ester of choline in the mycelium of a strain of Penicillium chrysogenum. J. Amer. chem. Soc. 77, 1676.

Egami, F. \& Itahashi, M. (1951). Biochemical studies on choline sulfate ester. 1. Aspergillus oryzae grows in a medium with the choline sulfate ester as sulfur source. Igaku Seibutsugaku (Med. \& Biol.), 19, 292.

Hockenhuld, D. J. D. (1948). Studies in penicillin production by Penicillium notatum in surface culture. 2. Further studies in the metabolism of sulphur. Biochem. J. 43, 498.

Hockenhull, D. J. D. (1949). The sulphur metabolism of mould fungi: the use of 'biochemical mutant' strains of Aspergillus nidulans in elucidating the biosynthesis of cystine. Biochim. biophys. Acta, 3, 326.

Horowitz, N. H. \& Beadle, G. W. (1943). A microbiological method for the determination of choline by use of a mutant of neurospora. J. biol. Chem. 150, 325.

Itahashi, M. (1954). Sulphur metabolism of Aspergillus oryzae. Res. Rep., Aichi Educational College, Japan, 4, 37.

KAJI, A. \& McElroy, W. D. (1958). Enzymic formation of choline sulphate. Biochim. biophys. Acta, 30, 190.

LiNDBERG, B. (1955a). Studies on the chemistry of lichens. VIII. Investigation of a Dermatocarpon and some Rocella species. Acta chem. scand. 9, 917.

LindBerg, B. (1955b). Methylated taurines and choline sulphate in red algae. Acta chem. scand. 9, 1323. 
Raistrick, H. \& Vincent, J. M. (1948). Studies in the biochemistry of microorganisms 77. A survey of fungal metabolism of inorganic sulphates. Biochem. J. 43, 90.

SChNeider, J. J. \& Lewbart, M. L. (1956). Enzymatic synthesis of steroid sulfates. J. biol. Chem. $222,787$.

Spencer, B. \& Harada, T. (1959). The role of choline sulphate in the sulphur metabolism of fungi. Biochem. $J$. (in the Press).

Stevens, C. M. \& Vohra, P. (1955). Occurrence of choline sulfate in Penicillium chrysogenum. J. Amer. chem. Soc. 77, 4935.

Strauss, B. S. \& Minagawa, T. (1959). The formation of methionine by a methionine-requiring mutant of Neurospora crassa. J. gen. Microbiol. 20, 237.

WICKBERG, B. (1956). Isolation of N-D-2, 3-dihydroxy-n-propyl-taurine from Gigartina leptorhynchos. Acta chem. scand. 10, 1097.

WICKBERG, B. (1957). Isolation of 2-L-amino-3-hydroxy-1-propane sulphonic acid from Polysiphana fastigiata. Acta chem. scand. 11, 506.

Windisch, S. (1948). Ủber Torulopsis utilis und die Pseudomycelfrage. Braurwelt, 9, 467.

Woon, T. (1956). A laboratory electrodialyser and desalter. Biochem. J. 62, 611.

Woolley, D. W. \& Peterson, W. H.(1937). The chemistry of mold tissue. XIV. Isolation of cyclic choline sulfate from Aspergillus sydorei. J. biol. Chem. 122, 213.

(Received 24 September 1959) 